\title{
Tratamento Terciário de Esgoto Sanitário Proveniente de Lagoa de Polimento Utilizando Sistema de Coagulação/Precipitação Seguido de Radiação Ultravioleta
}

\author{
Tertiary Treatment of Sanitary Sewage from Polishing Pond Using \\ System of Coagulation/Precipitation Followed by Ultraviolet Radiation
}

\author{
Victória Regina Celso Monteiro'; Carlos Magno de Sousa Vidal2; Jeanette Beber de \\ Sousa $^{3}$; Grasiele Soares Cavallini ${ }^{4}$
}

\begin{abstract}
Resumo
Investigou-se nesse estudo o processo de coagulação/precipitação seguido da radiação ultravioleta visando o tratamento terciário de esgoto sanitário proveniente de lagoas de polimento. Para isto foram feitos ensaios de laboratório em jart-test para simular a coagulação e em reator UV para simular a desinfecção, variando-se as condições operacionais. O processo demonstrou bom desempenho, verificando-se moderada remoção de turbidez (27\%-66\%), DQO (22\%-53\%), cor aparente (22\%$64 \%)$, cor verdadeira (34\%-60\%), fósforo (31\%-52\%), sólidos totais $(2 \%-21 \%)$ e sólidos suspensos (10\%-30\%). A fim de melhorar o processo de coagulação foram realizados testes com polímeros aniônicos e catiônicos, sendo que o catiônico apresentou melhores resultados. A dosagem de coagulante considerada ótima foi $60 \mathrm{mg} . \mathrm{L}^{-1}$ de cloreto férrico combinado com $20 \mathrm{mg} . \mathrm{L}^{-1}$ de polímero cationico. Na melhor configuração operacional obtida alcançou-se inativação de 4,65 log para CT e 4,60 log para E. coli, obtendo-se remoções de $62,7 \%$ de turbidez, $65,3 \%$ e $69,7 \%$ de cor aparente e cor verdadeira respectivamente, $50,3 \%$ de DQO e $47,3 \%$ de sólidos suspensos. Conclui-se que este processo pode ser considerado adequado para a remoção de poluentes de uma lagoa de polimento, mas deve ser observada a qualidade do efluente quanto à presença excessiva de algas que pode prejudicar o tratamento, dificultando o processo.

Palavras-chave: Esgoto sanitário. Coagulação. Desinfecção ultravioleta.
\end{abstract}

\begin{abstract}
In this research the process of coagulation/precipitation followed by ultraviolet disinfection was investigated for tertiary treatment of sewage from polish pond. Were done laboratory tests using jarttest to simulate coagulation and in reactor UV to simulate disinfection, varying operational conditions. The process demonstrated a good performance, had been verified moderate removal of turbidity $(27 \%$ $66 \%)$, COD (22\%-53\%), apparent color (22\%-64\%), real color $(22 \%-64 \%)$, phosphorus $(31 \%-52 \%)$, total solids (31\%-52\%) and suspended solids (10\%-30\%). To improve the process of coagulation were realized tests with anionic and cationic polymers, and the cationic showed the best results. The dose of coagulant considered optimal was $60 \mathrm{mg} \cdot \mathrm{L}^{-1}$ of ferric chloride combined with $20 \mathrm{mg}$. $\mathrm{L}^{-1}$ of polymer cationic. In the best operational configuration was obtained inactivation of 4,65 log to CT, and 4,60
\end{abstract}

\footnotetext{
${ }^{1}$ Engenheira Ambiental pela Universidade Estadual do Centro-Oeste; vicregina@hotmail.com.

2 Docente do Departamento de Engenharia Ambiental da Universidade Estadual do Centro-Oeste; cacavidal@yahoo.com.br.

3 Docente do Departamento de Engenharia Ambiental da Universidade Estadual do Centro-Oeste; jeanettebeber@yahoo.com.br.

${ }^{4}$ Técnica do Laboratório de Saneamento Ambiental e Qualidade da Água do Departamento de Engenharia Ambiental da Universidade Estadual do Centro-Oeste; grasielesoares@gmail.com.
} 
$\log$ to $E$. coli, obtaining $62,7 \%$ of removal for turbidity, $65,3 \%$ and $69,7 \%$ of apparent color and real color respectively, $50,3 \%$ of COD and $47,3 \%$ of suspended solids. In conclusion this process can be considered suitable for the removal of pollutants from a polish pond, but should be observed the quality of the effluent for the presence excessive of algae that can harm the treatment, making the process difficult.

Keywords: Sewage. Coagulation. Ultraviolet disinfection.

\section{Introdução}

$\mathrm{O}$ atual cenário brasileiro referente ao tratamento de esgoto sanitário ainda se mostra precário e insuficiente em várias regiões do país e por esse motivo se justifica a busca constante por melhorias nesses processos de tratamento que visam evitar a degradação do meio ambiente e a manutenção da saúde pública.

O tratamento mais utilizado e implantado na etapa secundária é o tratamento biológico, tanto sistemas aeróbios quanto anaeróbios. O reator anaeróbio de manta de lodo (UASB) é muito empregado no Brasil devido ao seu baixo custo quando comparado aos sistemas aeróbios, o que implica em economia nas etapas de implantação e operação. Além disso, gera um lodo em elevado processo de digestão, adensado e em menor quantidade em comparação aos sistemas aeróbios. Porém, este tipo de reator alcança em média, em torno de $70 \%$ de remoção de $\mathrm{DBO}$, valor este que em muitas ocasiões pode não satisfazer o padrão de emissão e de qualidade do corpo receptor, a depender das características de vazão e DBO do efluente final da ETE e do corpo receptor. Portanto, em muitos casos, o tratamento é complementado com as lagoas de polimento, que, embora ocupem grandes áreas, melhoram a qualidade do efluente a ser lançado (VON SPERLING, 2005).

As lagoas de polimento apesar de apresentarem efluentes de boa qualidade, ainda deixam residuais de matéria orgânica, sólidos em suspensão, nutrientes e outros poluentes, sendo necessário um tratamento adicional a fim de atender a padrões mais exigentes da legislação e ainda possibilitar o reúso da água para diferentes objetivos.
A coagulação seguida de precipitação tem sido cada vez mais empregada como alternativa de tratamento terciário de esgotos. O processo é iniciado com a aplicação do coagulante, que promove a desestabilização química das partículas presentes nas águas residuárias. Desta forma, aumenta-se a tendência de agregação ou fixação dos colóides, já que estes possuem em suas superfícies uma dupla camada elétrica que impede a ligação das partículas. Sais de ferro ou alumínio, cal e polímeros orgânicos sintéticos ou naturais são alguns dos agentes que podem ser empregados neste processo químico que é consumado em questão de segundos. Após, inicia-se a floculação e a separação dos flocos (decantação), etapas onde prevalecem os aspectos físicos do processo e por isso demandam alguns minutos (CHERNICHARO, 2001).

Porém, a coagulação não remove com eficiência microrganismos patogênicos presentes no esgoto, por isso é necessário que seja aplicado um processo de desinfecção posterior. Vários processos de desinfecção são conhecidos e utilizados atualmente como cloro, ácido peracético, permanganato de potássio, radiação ultravioleta, entre outros e, por esta razão é necessário que seja feita uma escolha adequada do desinfetante, de acordo com a necessidade de desinfecção e qualidade do efluente.

A desinfecção por radiação ultravioleta é um mecanismo físico que emite luz e promove uma reação fotoquímica que altera componentes essenciais para o funcionamento celular (DNA e RNA), os quais são indispensáveis para a reprodução. Os danos que a radiação provoca promovem a destruição ou inativação destes, 
além de oxidar a matéria orgânica, remover ferro e manganês, garantindo a segurança sanitária do efluente (UNITED STATES ENVIRONMENTAL PROTECTION AGENCY, 1999).

Para a radiação ultravioleta, Wrigth e Cairns (1998) apud Aguiar et al., (2002) afirmam que o comprimento de onda de $254 \mathrm{~nm}$ é onde se observa a maior ação germicida e a formação de subprodutos é considerada mínima, não tendo sido observadas a formação de agentes carcinógenos ou mutagênicos.

O cloro, por exemplo, gera preocupação pela possibilidade de formação de subprodutos organoclorados, que podem ser cancerígenos, teratogênicos ou mutagênicos, prejudicando a saúde humana. O ozônio por sua vez tem eficiência comparável a do cloro, com a vantagem de não deixar resíduos, porém apresenta alto custo na instalação e operação, pois tem a necessidade de ser gerado in situ, além de exigir mão de obra especializada (OLIVEIRA, 2003).

De acordo com Oliveira (2003), regiões áridas e semi-áridas e também regiões onde a demanda de água é elevada, vêm buscando continuamente novas alternativas para complementar a pequena disponibilidade hídrica. Nestes casos é que devem ser consideradas as águas residuárias visando reúso para fins menos restritivos. Os maiores potenciais de reúso são:

- $\quad$ irrigação de parques, jardins e gramados;

- $\quad$ reservas de proteção contra incêndios;

- sistemas decorativos aquáticos (fontes, chafarizes, espelhos e quedas d'água);

- descarga sanitária em banheiros públicos e em edifícios comerciais e industriais;

- lavagem de trens e ônibus públicos.

O sistema aqui proposto tem grande potencial de gerar efluente para os tipos de reúso citados, com a coagulação conferindo ao esgoto a qualidade necessária para que este seja submetido à desinfecção por radiação ultravioleta, que o complementa, resultando em um efluente final de boa qualidade. O objetivo desta pesquisa foi avaliar a eficiência do processo de coagulação/precipitação seguido por radiação ultravioleta como alternativa de tratamento terciário de esgoto sanitário proveniente de lagoa de polimento.

\section{Materiais e Métodos}

Neste trabalho coletou-se amostra de esgoto da lagoa de polimento da Estação de Tratamento de Esgoto Rio das Antas, Irati-PR. As análises foram realizadas no laboratório de Saneamento Ambiental e Qualidade da Água da Universidade Estadual do Centro-Oeste/PR, campus Irati.

AETE de Irati é composta por grade, desarenador, calha pharsall que distribui a vazão afluente para dois reatores anaeróbios, um UASB e um RALF, cujos efluentes são unidos novamente na lagoa de polimento e então lançados no corpo hídrico.

Inicialmente foi separada uma amostra do efluente da lagoa para caracterização, sendo avaliados os parâmetros: $\mathrm{pH}$, temperatura, turbidez, DQO, sólidos totais, sólidos suspensos, cor aparente e cor verdadeira, alcalinidade e fósforo.

Para a simulação da coagulação/floculação/ decantação, foi utilizado o jar-test composto por 6 jarros e por dispositivo que controla a velocidade de mistura do efluente, promovendo uma mistura homogênea e com o gradiente desejado.

Nos três primeiros ensaios, foram necessários aproximadamente $12 \mathrm{~L}$ de efluente, para cada batelada, a fim de completar a capacidade de $2 \mathrm{~L}$ de cada jarro do jar-test. Utilizou-se como agente coagulante o cloreto férrico $\left(\mathrm{FeCl}_{3} \cdot 6 \mathrm{H}_{2} \mathrm{O}\right)$ na dosagem de $60 \mathrm{mg} . \mathrm{L}^{-1}$, gradiente de mistura rápida de $500 \mathrm{~s}^{-1}$, tempo de mistura rápida de $30 \mathrm{~s}$, gradiente de mistura lenta de $50 \mathrm{~s}^{-1}$, tempo de mistura lenta de 10 minutos e tempo de sedimentação de 7 minutos e 30 segundos, culminando na velocidade de sedimentação de $0,8 \mathrm{~cm} / \mathrm{min}$. As alíquotas de 
sobrenadante (coagulado) recolhidas para análise foram retiradas com seringa, $6 \mathrm{~cm}$ abaixo da lâmina de efluente no jar-test. As condições operacionais empregadas nesta parte do estudo foram baseadas nos dados obtidos no trabalho de Garcia (2010).

A eficiência da coagulação foi avaliada com base na porcentagem de remoção de turbidez, DQO, sólidos totais e sólidos suspensos, cor aparente e cor verdadeira e fósforo, sendo empregadas as metodologias descritas no Standard Methods for Examination of the Water and Wastewater (AMERICAN PUBLIC HEALTH ASSOCIATION, 1998) para análise destes parâmetros.

O reator ultravioleta de bancada (Figura 1) utilizado é constituído de chapa de aço inoxidável, possui $40 \mathrm{~cm}$ de largura, $45 \mathrm{~cm}$ de comprimento e $15 \mathrm{~cm}$ de profundidade e é composto por 6 lâmpadas de baixa pressão de vapor de mercúrio, de $15 \mathrm{~W}$ de potência cada, as quais possuem interruptores independentes.

Figura 1 - Esquema do reator UV de bancada empregado na pesquisa.
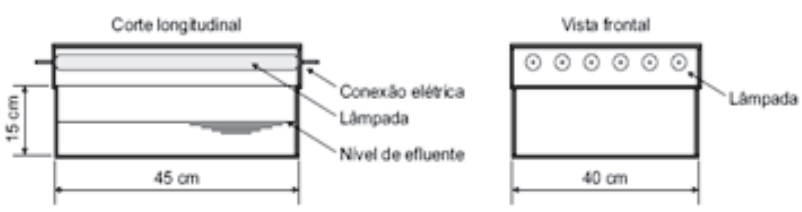

(a) Reatcr fotoquimico

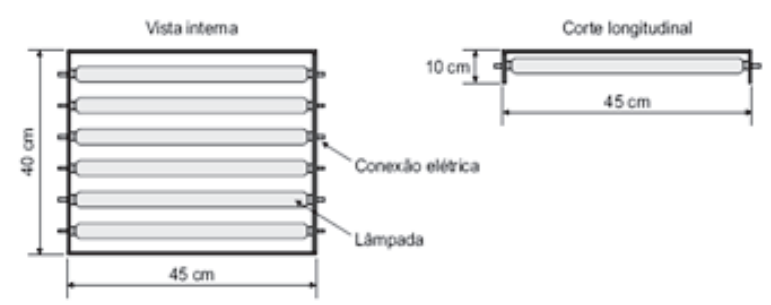

(b) Cúpula refletora

Fonte: Bilotta e Daniel (2007).

Foram realizadas três bateladas de ensaios no jartest idênticas a fim de se obter a quantidade necessária de efluente coagulado para ser levado ao reator UV e ser atingida uma lâmina de $4 \mathrm{~cm}$. $O$ reator $U V$ foi operado com três lâmpadas ligadas em tempos de exposição de 20, 40, 60 e 90 segundos, e sob agitação magnética constante. Para os referidos tempos de exposição, foram obtidas as seguintes doses de radiação 10,54; 21,$08 ; 31,62$ e 47,43 mWs.cm² .

Foram coletadas amostras de esgoto irradiado em todos os tempos de exposição para realização dos testes para E. coli e Coliformes Totais, de acordo com o método da membrana filtrante e utilizando o meio de cultura Chromocult Coliform Agar.

Nos dois ensaios seguintes repetiram-se os mesmos procedimentos do ensaio anterior, a fim de se verificar a eficácia das configurações operacionais adotadas. A partir do terceiro ensaio, utilizaram-se 6 lâmpadas para o tratamento com radiação ultravioleta, a fim de aumentar o grau de inativação dos microrganismos indicadores de contaminação, obtendo-se então as seguintes doses de radiação: 21,14; 42,28; 63,42 e 95,13 mWs.cm-2, para os mesmos tempos de exposição.

Devido à necessidade de melhoria da coagulação/ precipitação, realizou-se um quarto ensaio, a fim de se testar a utilização de polímeros, visando-se obter menores valores de turbidez e sólidos residuais e assim melhorar a eficiência da desinfecção com radiação ultravioleta.

Segundo Fagundes (2010), o uso de polímeros como auxiliares de floculação, tem por objetivo aumentar a resistência dos flocos contra as forças de cisalhamento e diminuir as dosagens de coagulantes primários. Os polímeros podem ser classificados como catiônicos, aniônicos, anfolíticos e nãoiônicos, e sua interação entre os seus sítios ativos e os colóides promovem sua aglomeração, diminuindo assim sua repulsão e facilitando de maneira significativa a formação de flocos e a posterior decantação.

Concentrações de 0,$5 ; 1,0 ; 2,0$ e 3,0 mg. $\mathrm{L}^{-1}$ de polímero aniônico em pó e 5,0; 10,0 e 20,0 mg.L $\mathrm{L}^{-1}$ de polímero catiônico em emulsão foram testadas, juntamente com 40, 60 e $80 \mathrm{mg} . \mathrm{L}^{-1}$ de cloreto férrico, a fim de se obter uma dosagem ótima 
da combinação de coagulante com polímero e também para se determinar qual polímero foi mais eficiente para o tratamento do efluente da lagoa. As concentrações de polímeros/coagulantes foram baseadas no trabalho de Ferrari et al. (2005) e Sttip et al., (2010). As doses maiores de polímero catiônico utilizadas em relação as de aniônico são devidas ao primeiro ser amostra do produto em emulsão e a do segundo na forma sólida (em pó). $\mathrm{Na}$ forma sólida a concentração do polímero é de $100 \%$. As emulsões contém, além do polímero de interesse, agentes emulsificantes e água, podendo o produto ser aplicado de forma direta. Com isso, a concentração do polímero de interesse na forma de emulsão é menor do que na forma sólida. A maioria da empresas fabricantes de polímero não informa a concentração real do produto e por isso se torna mais seguro trabalhar com dosagens que considerem a massa do produto na sua forma comercial (independente se o produto esta na forma sólida ou em emulsão), como foi feito neste trabalho. Aliado a isto vale ressaltar a afirmação de Kriebel (2002), apud Quartarolli (2012), que afirma que polímeros em emulsão têm atividade em torno de $40 \%$ enquanto os em pó em torno de $100 \%$.

Foram adotados para a primeira e segunda bateladas, os mesmos tempos de mistura rápida e lenta, e os mesmos gradientes de mistura dos ensaios anteriores, pois Amirtharajah (1989 apud AISSE et al., 2001), indica tempos de mistura rápida entre 30 e 60 segundos, com gradientes entre 400 e $650 \mathrm{~s}^{-1}$ na utilização de polímeros. A terceira batelada foi realizada com 60 segundos de mistura rápida, sem mistura lenta, para evitar a quebra dos flocos que foram formados rapidamente, pois segundo o mesmo autor, a quebra dos flocos diminui a eficiência do processo de coagulação/floculação. Seguiu-se então diretamente para a sedimentação de 10 minutos, a qual foi a mesma para as 3 bateladas (velocidade de sedimentação de $0,6 \mathrm{~cm} / \mathrm{min}$ ).

No último ensaio o efluente foi novamente caracterizado, e então foi aplicada a dosagem de coagulante e polímero considerada ótima de acordo com os resultados anteriores. Os tempos de mistura rápida e lenta e os gradientes de velocidade foram os mesmos dos três primeiros ensaios e o tempo de sedimentação foi de 10 minutos, sendo a velocidade de sedimentação de $0,6 \mathrm{~cm} / \mathrm{min}$. Foram analisados os mesmos parâmetros e o efluente foi então submetido ao reator ultravioleta.

$\mathrm{Na}$ Figura 2 verifica-se o fluxograma com a grade de ensaios empregada na pesquisa bem como as diferentes condições operacionais estudadas.

Figura 2 - Fluxograma da sequencia de ensaios realizados, dosagens de coagulantes utilizadas e número de lâmpadas ligadas em cada ensaio.

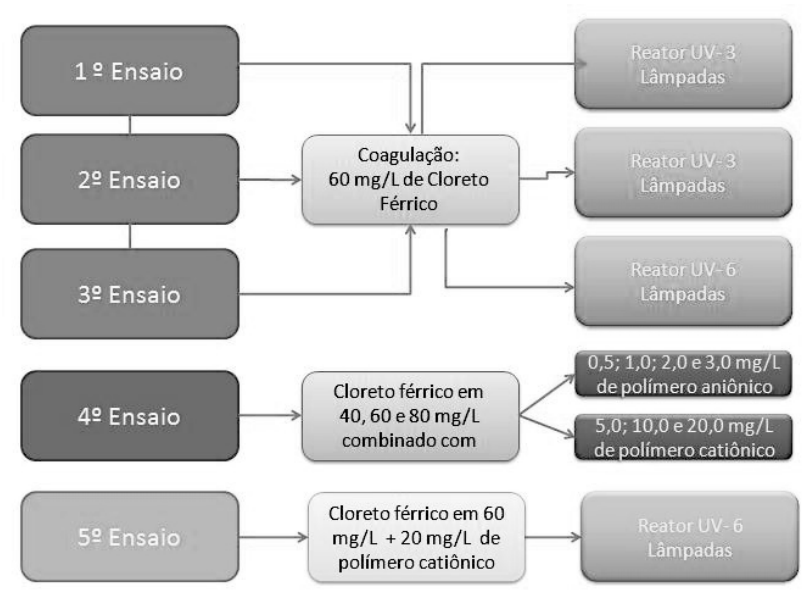

Fonte: Os autores

\section{Resultados e Discussão}

$\mathrm{Na}$ Tabela 1 podem ser verificadas as características do esgoto coletado da lagoa de polimento para os ensaios iniciais. 
Tabela 1 - Caracterização do efluente da lagoa utilizado nos três ensaios iniciais.

\begin{tabular}{lccc}
\hline PARÂMETROS & $\begin{array}{c}\mathbf{1}^{\mathbf{0}} \\
\text { Ensaio }\end{array}$ & $\begin{array}{c}\mathbf{2}^{\mathbf{0}} \\
\text { Ensaio }\end{array}$ & $\begin{array}{c}\mathbf{3}^{\mathbf{0}} \\
\text { Ensaio }\end{array}$ \\
\hline \hline pH & 7,2 & 7,6 & 7,3 \\
\hline Temperatura $\left({ }^{\circ} \mathrm{C}\right)$ & 28,2 & 21,0 & 22,0 \\
\hline Turbidez $(u T)$ & 26,7 & 22,9 & 20,6 \\
\hline Cor Aparente $(u \mathrm{C})$ & 551,0 & 530,0 & 473,0 \\
\hline Cor Verdadeira $(u \mathrm{C})$ & 158,0 & 193,0 & 260,0 \\
\hline DQO $\left(\mathrm{mg} \cdot \mathrm{L}^{-1}\right)$ & 90,6 & 139,1 & 132,0 \\
\hline Alcalinidade $(\mathrm{mgCaCO} / \mathrm{mL})$ & 30,4 & 44,1 & 87,0 \\
\hline Sólidos Totais $\left(\mathrm{mg} \cdot \mathrm{L}^{-1}\right)$ & 267,0 & 312,0 & 347,0 \\
\hline Sólidos Suspensos $\left(\mathrm{mg}^{-L^{-1}}\right)$ & 80,0 & 64,0 & 58,0 \\
\hline Fósforo $\left(\right.$ mg. $\left.L^{-1}\right)$ & 3,2 & 1,4 & 4,4 \\
\hline
\end{tabular}

Fonte: Os autores

De acordo com a Tabela 2 verifica-se que a coagulação com cloreto férrico possibilitou remoção moderada de DQO, cor, sólidos e fósforo, sendo a maior redução de turbidez, no $1^{\circ}$ ensaio, que alcançou $66 \%$. Em geral, as remoções foram parecidas no $1^{\circ}$ e no $2^{\circ}$ ensaios, porém, reduziram significativamente no $3^{\circ}$ ensaio, onde se obteve $27 \%$ de remoção de turbidez, $2 \%$ de sólidos e $10 \%$ de sólidos suspensos.

Tabela 2 - Caracterização do esgoto coagulado com uso apenas de cloreto férrico e as respectivas remoções de poluentes.

\begin{tabular}{l|c|c|c|c|c|c}
\hline PARÂMETROS & \multicolumn{2}{|c|}{$\mathbf{1}^{\circ}$ Ensaio } & \multicolumn{2}{c|}{$\mathbf{2}^{\circ}$ Ensaio } & \multicolumn{2}{c}{$\mathbf{3}^{\circ}$ Ensaio } \\
\hline \hline & Coagulado & $\%$ & Coagulado & $\%$ & Coagulado & $\%$ \\
\hline pH & - & - & 7,05 & - & 7,03 & - \\
\hline Temperatura $\left({ }^{\circ} \mathrm{C}\right)$ & 28,2 & & 21 & & 22 & \\
\hline Turbidez $(u T)$ & 9,14 & 66 & 11,1 & 52 & 14,9 & 27 \\
\hline Cor Aparente $(u \mathrm{C})$ & 200 & 64 & 285 & 46 & 371 & 22 \\
\hline Cor Verdadeira $(u \mathrm{C})$ & 64 & 60 & 100 & 48 & 171 & 34 \\
\hline DQO $(\mathrm{mg} / \mathrm{L})$ & 43 & 53 & 65 & 53 & 90 & 22 \\
\hline Alcalinidade $(\mathrm{mgCaCO3/mL)}$ & 20,2 & - & 34,9 & - & 70 & - \\
\hline Sólidos Totais $(\mathrm{mg} / \mathrm{L})$ & 212 & 21 & 272 & 13 & 339 & 2 \\
\hline Sólidos Suspensos $(\mathrm{mg} / \mathrm{L})$ & $\mathbf{5 6}$ & 30 & 52 & 19 & 52 & 10 \\
\hline Fósforo $(\mathrm{mg} / \mathrm{L})$ & 0,78 & 31 & 0,83 & 42 & 2,12 & 52 \\
\hline
\end{tabular}

Fonte: Os autores 
De acordo com os resultados obtidos, tornouse interessante o teste da aplicação de polímero aniônico aliado ao cloreto férrico, em um $4^{\circ}$ ensaio, a fim de se obter coagulação mais eficiente, pois esta foi prejudicada pelo acúmulo de algas verificado no efluente do $3^{\circ}$ ensaio que de acordo com Ferrari et al., (2005), as algas exercem excessiva influência sobre diversos parâmetros do efluente, como turbidez, sólidos e DQO. Aliado a isso, as algas induzem a má formação de flocos, dificultando- se a desestabilização de colóides, assim, os flocos ficam leves e são impossibilitados de sedimentar adequadamente. Tal fato está associado à excessiva carga negativa presente na superfície das algas.

Na Tabela 3 e na Figura 3 encontram-se os resultados obtidos na inativação dos microrganismos pela radiação ultravioleta nas amostras de sobrenadante (coagulado) da coagulação dos 3 primeiros ensaios realizados.

Tabela 3 - Remoção de Coliformes Totais e E.coli de acordo com o tempo de exposição e dose de radiação para os três primeiros ensaios.

\begin{tabular}{|c|c|c|c|}
\hline Ensaio 1 & Dose & $\log \left(\mathbf{N} / \mathbf{N}_{0}\right)$ & $\log \left(\mathbf{N} / \mathbf{N}_{0}\right)$ \\
\hline Tempo (s) & mWs.cm-2 & $\begin{array}{c}\text { Coliformes } \\
\text { Totais }\end{array}$ & $\begin{array}{c}\text { Escherichia } \\
\text { coli } \\
\end{array}$ \\
\hline 20 & 10,54 & - & - \\
\hline 40 & 21,08 & $-3,000$ & $-4,470$ \\
\hline 60 & 31,62 & $-3,300$ & $-4,470$ \\
\hline 90 & 47,43 & $-4,300$ & $-5,000$ \\
\hline Ensaio 2 & Dose & $\log \left(\mathbf{N} / \mathbf{N}_{0}\right)$ & $\log \left(N / N_{0}\right)$ \\
\hline Tempo (s) & mWs.cm-2 & $\begin{array}{c}\text { Coliformes } \\
\text { Totais }\end{array}$ & $\begin{array}{c}\text { Escherichia } \\
\text { coli }\end{array}$ \\
\hline 20 & 10,54 & $-2,200$ & $-2,820$ \\
\hline 40 & 21,08 & $-3,500$ & $-4,000$ \\
\hline 60 & 31,62 & $-4,300$ & $-4,450$ \\
\hline 90 & 47,43 & $-4,600$ & $-5,300$ \\
\hline Ensaio 3 & Dose & $\log \left(N / N_{0}\right)$ & $\log \left(\mathbf{N} / \mathbf{N}_{0}\right)$ \\
\hline Tempo (s) & mWs.cm-2 & $\begin{array}{c}\text { Coliformes } \\
\text { Totais }\end{array}$ & $\begin{array}{c}\text { Escherichia } \\
\text { coli }\end{array}$ \\
\hline 20 & 21,14 & $-1,340$ & $-1,050$ \\
\hline 40 & 42,28 & $-3,260$ & $-2,900$ \\
\hline 60 & 63,42 & $-3,760$ & $-3,700$ \\
\hline 90 & 95,13 & $-4,080$ & $-4,600$ \\
\hline
\end{tabular}

Fonte: Os autores 
Figura 3 - Inativação de CT e E. coli das amostras do sobrenadante da coagulação, com diferentes doses de radiação, para os primeiros 3 ensaios realizados.

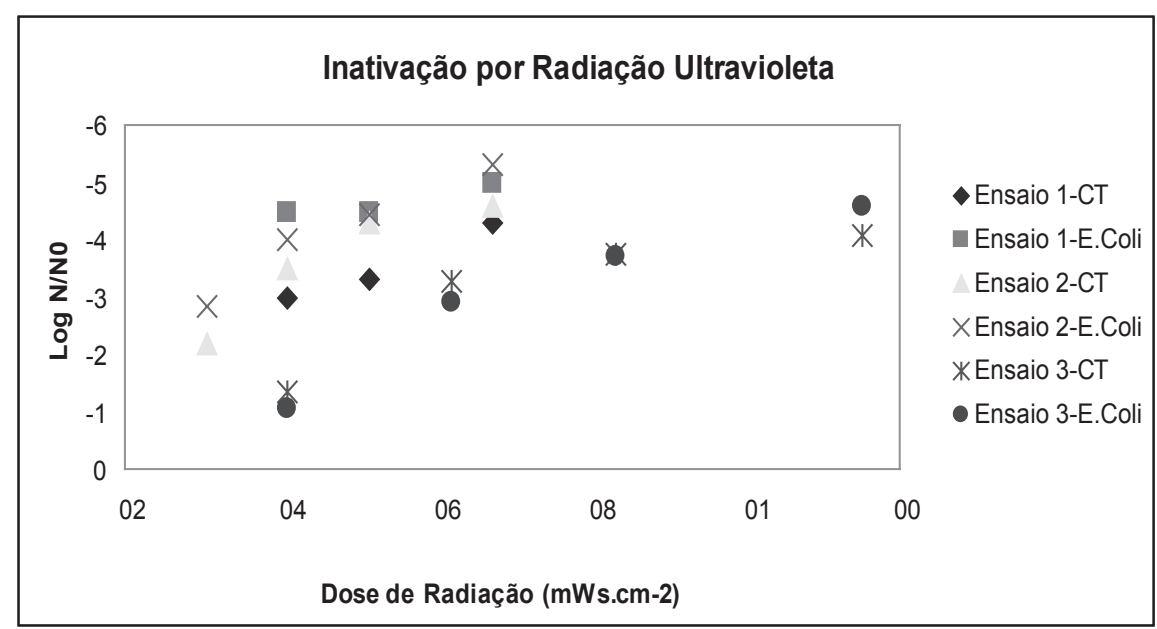

Fonte: Os autores

Observa-se que os ensaios 1 e 2 foram semelhantes, e diferiram do ensaio 3 , sendo a melhor inativação observada no $2^{\circ}$ ensaio, para E. coli, com 5,3 log, caracterizando um excelente resultado. Constata-se que a inativação não depende somente da dose de radiação aplicada, mas sim da qualidade do efluente que é submetido ao reator UV, pois a inativação não atingiu valores máximos, mesmo com as maiores doses aplicadas no $3^{\circ}$ ensaio, devido à ineficiente remoção de sólidos, a qual impediu um maior contato da radiação UV com os microrganismos.

Para o $4^{\circ}$ ensaio foram analisados somente quatro parâmetros, os quais são representativos da qualidade do efluente e são considerados importantes para o processo ultravioleta aplicado posteriormente. Neste ensaio o efluente de saída da lagoa apresentou turbidez de 17,6 uT, cor de $402 \mathrm{uC}$, concentração de fósforo de $5,7 \mathrm{mg} . \mathrm{L}^{-1} \mathrm{e}$ a DQO de $111 \mathrm{mg} \cdot \mathrm{L}^{-1}$.

Pode-se constatar então, na Tabela 4 que o polímero aniônico não removeu turbidez e cor com eficiência do efluente da lagoa, já que a maior remoção foi de $15 \%$ e $18 \%$, respectivamente. Provavelmente isto ocorreu porque as algas, segundo Friedman et al. (1977) apud Rocha et al., (1998), causam repulsão eletrostática devido suas cargas superficiais, já que podem ser descritas como biocolóides hidrofílicos com carga elétrica superficial negativa. De acordo com Chen e Yeh (2005) a remoção de algas por tratamento convencional é mais difícil que a remoção de partículas inorgânicas devido a baixa densidade específica das algas, bem como sua motilidade, características morfológicas e carga superficial negativa, além disso, é importante considerar que o tratamento não deve romper as células, pois pode haver liberação de toxinas nocivas.

No entanto, obteve-se moderada remoção de fósforo, a qual atingiu $61 \%$, na dosagem de $60 \mathrm{mg} . \mathrm{L}^{-1}$ de cloreto férrico com $1,0 \mathrm{mg} . \mathrm{L}^{-1} \mathrm{de}$ polímero, e remoção de DQO, que atingiu 27\% na dosagem de $40 \mathrm{mg} . \mathrm{L}^{-1}$ de cloreto férrico com 1,0 mg. $\mathrm{L}^{-1}$ de polímero aniônico. 
Tabela 4 - Concentrações residuais e eficiências de remoção de Turbidez, Cor Aparente, Fósforo e DQO nos ensaios com cloreto férrico e polímero aniônico em diferentes dosagens.

\begin{tabular}{|c|c|c|c|c|c|c|c|c|c|}
\hline C.F.(mg/L) & P. A. (mg/L) & Turbidez & $\%$ & Cor & $\%$ & Fósforo $\%$ & DQO & $\%$ \\
\hline \hline 40 & 0 & 22,9 & & 442 & & 3,64 & 36 & 83 & 25 \\
\hline 40 & 0,5 & 15 & 15 & 361 & 10 & 2,88 & 49 & 91 & 18 \\
\hline 40 & 1 & 17,2 & 2,3 & 370 & 8 & 3,32 & 42 & 81 & 27 \\
\hline 60 & 0 & 19,1 & & 414 & & 2,48 & 57 & 91 & 18 \\
\hline 60 & 0,5 & 15,5 & 12 & 354 & 12 & 2,52 & 56 & 96 & 14 \\
\hline 60 & 1 & 15 & 15 & 329 & 18 & 2,24 & 61 & 86 & 23 \\
\hline
\end{tabular}

C.F= Cloreto Férrico, P.A.= Polímero Aniônico, \%= Remoção.

Fonte: Os autores

Pode ser destacado, pelas tabelas 5 e 6 , o melhor desempenho do polímero catiônico, se comparado ao polímero aniônico, pois são observadas maiores remoções para quase todos os parâmetros.

Tabela 5 - Concentrações residuais e eficiências de remoção de Turbidez, Cor Aparente, Fósforo e DQO em ensaios com cloreto férrico e polímero catiônico e aniônico em diferentes dosagens.

\begin{tabular}{|c|c|c|c|c|c|c|c|c|c|}
\hline C.F. (mg/L) & P. C. $(\mathrm{mg} / \mathrm{L})$ & Turbidez & $\%$ & Cor & $\%$ & Fósforo & $\%$ & DQO & $\%$ \\
\hline 40 & 10 & 15,4 & 13 & 359 & 11 & 3,32 & 42 & 86 & 23 \\
\hline 40 & 20 & 15,3 & 13 & 274 & 32 & 2,96 & 48 & 63 & 43 \\
\hline 60 & 10 & 13,3 & 24 & 303 & 25 & 1,6 & 72 & 77 & 31 \\
\hline \multirow[t]{2}{*}{60} & 20 & 8,26 & 53 & 208 & 48 & 0,92 & 83 & 48 & 57 \\
\hline & P.A. (mg/L) & & & & & & & & \\
\hline 60 & 2 & 14,6 & 17 & 338 & 16 & 2,84 & 50 & 95 & 14 \\
\hline 60 & 3 & 14 & 20 & 355 & 12 & 2,92 & 49 & 84 & 24 \\
\hline
\end{tabular}

C.F= Cloreto Férrico, P.C. = Polímero Catiônico, P.A.= Polímero Aniônico, \%= Remoção.

Fonte: Os autores

Tabela 6 - Concentrações residuais e eficiências de remoção de Turbidez, Cor Aparente, Fósforo e DQO em ensaios com cloreto férrico e polímero catiônico em diferentes dosagens.

\begin{tabular}{|c|c|c|c|c|c|c|c|c|c|}
\hline C.F. (mg/L) & P.C. (mg/L) & Turbidez & $\%$ & Cor & \% & Fósforo $\%$ & DQO & $\%$ \\
\hline \hline 40 & 20 & 11 & 38 & 260 & 35 & 2,56 & 55 & 57 & 49 \\
\hline 40 & 10 & 14,5 & 18 & 361 & 10 & 3,36 & 41 & 70 & 37 \\
\hline 40 & 5 & 19,2 & & 440 & & 3,64 & 36 & 86 & 23 \\
\hline 80 & 10 & 8,4 & 52 & 210 & 48 & 0,84 & 85 & 52 & 53 \\
\hline 80 & 5 & 15 & 15 & 379 & 5,7 & 2,48 & 57 & 71 & 36 \\
\hline & 10 & 12,4 & 30 & 322 & 20 & 3,52 & 38 & 87 & 21 \\
\hline
\end{tabular}

C.F.= Cloreto Férrico, P.C. $=$ Polímero Catiônico, $\%=$ Remoção.

Fonte: Os autores 
Da Tabela 5, os melhores resultados foram obtidos para a dosagem de $60 \mathrm{mg} . \mathrm{L}^{-1}$ de cloreto férrico com $20 \mathrm{mg} . \mathrm{L}^{-1}$ de polímero catiônico, obtendo-se $53 \%$ de remoção de turbidez, $48 \%$ de remoção de cor aparente, $83 \%$ e $57 \%$ para fósforo e DQO, respectivamente. Na tabela 6 , o melhor rendimento foi com a dosagem de $80 \mathrm{mg} . \mathrm{L}^{-1}$ de cloreto férrico com $10 \mathrm{mg} . \mathrm{L}^{-1}$ de polímero catiônico, sendo 52\% de remoção de turbidez, $48 \%$ de remoção de cor aparente, $85 \%$ para fósforo e $53 \%$ para DQO.

Mediante estes resultados, considera-se que o polímero catiônico é mais eficiente para a coagulação de efluentes de lagoa de polimento que contém algas, como assim foi constatado por Tilton et al. (1972) apud Rocha et al., (1998), que realizou estudos de floculação de algas com polímeros sintéticos, e estes indicaram que a adsorção de polímeros catiônicos revertem as cargas negativas das superfícies das algas, reduzindo a força de repulsão existente.

A dosagem de cloreto férrico considerada ótima foi $60 \mathrm{mg} . \mathrm{L}^{-1}$, com $20 \mathrm{mg} . \mathrm{L}^{-1}$ de polímero catiônico, representando significativos valores de remoção, inclusive para o fósforo, resultando em um efluente de ótima qualidade. É Importante salientar que o fósforo, juntamente com o nitrogênio representa o principal fator de estímulo para eutrofização dos corpos d'água pelo excesso de nutrientes, levando ao crescimento excessivo de algas (VON SPERLING, 2005).

A Tabela 7 apresenta os parâmetros avaliados para o efluente da lagoa, as concentrações residuais após coagulação com cloreto férrico e polímero catiônico na dosagem considerada mais eficiente, e as respectivas porcentagens de remoção.

Tabela 7 - Caracterização do efluente, concentrações residuais e porcentagem de remoção dos poluentes por coagulação com cloreto férrico e polímero catiônico no ensaio otimizado.

\begin{tabular}{lccc}
\hline PARÂMETROS & Eflluente da Lagoa & Amostra Tratada & \% Remoção \\
\hline \hline pH & 7,46 & 7,1 & \\
\hline Temperatura $\left({ }^{\circ} \mathrm{C}\right)$ & 19 & 19 & \\
\hline Turbidez $(u T)$ & 18,9 & 7,05 & 62,7 \\
\hline Cor Aparente $(u \mathrm{C})$ & 447 & 155 & 65,3 \\
\hline Cor Verdadeira $(u \mathrm{C})$ & 274 & 83 & 69,7 \\
\hline DQO $(\mathrm{mg} / \mathrm{L})$ & 129 & 64 & 50,3 \\
\hline Alcalinidade $(\mathrm{mgCaCO} / \mathrm{mL})$ & 70 & 73,6 & \\
\hline Sólidos Totais $(\mathrm{mg} / \mathrm{L})$ & 413 & 347 & 16 \\
\hline Sólidos Suspensos $(\mathrm{mg} / \mathrm{L})$ & 76 & 40 & 47,3 \\
\hline Fósforo $(\mathrm{mg} / \mathrm{L})$ & 6,5 & 4,08 & 37,2 \\
\hline
\end{tabular}

Fonte: Os autores

A Figura 4 apresenta um comparativo das nos diferentes ensaios realizados. remoções para os principais parâmetros analisados 
Figura 4 - Porcentagens de remoção obtidas dos principais parâmetros para os ensaios realizados com $(\mathrm{CF})$ : Cloreto Férrico e (PC): Polímero Catiônico.

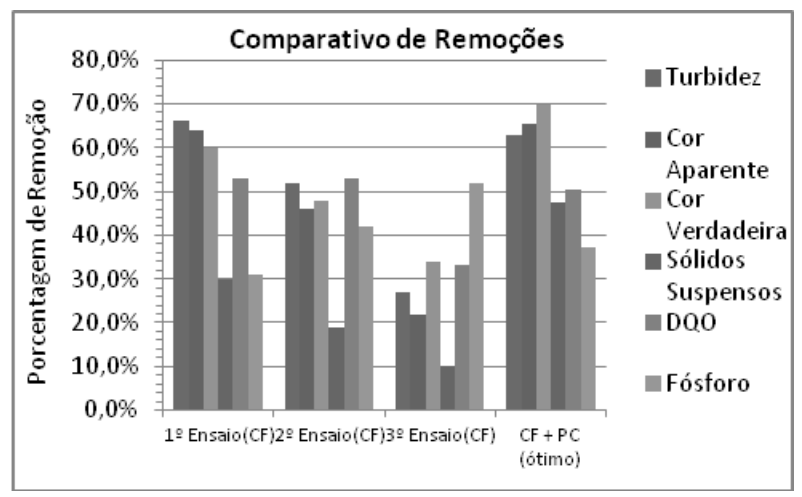

Fonte: Os autores

Analisando a Tabela 6, facilmente observase as maiores eficiências de remoção obtidas no ensaio ótimo com polímero catiônico. A turbidez apresentou remoção de $62,7 \%$, cor aparente e cor verdadeira de $65,3 \%$ e $69,7 \%$, respectivamente e DQO apresentou remoção de 50,3\%.

Na Figura 4 observa-se que os valores de remoção foram superiores para praticamente todos os parâmetros no ensaio ótimo, alcançando as elevadas remoções obtidas no $1^{\circ}$ ensaio. Dessa forma, constata-se a eficácia da aplicação desta dose, quando o efluente sofre alguma interferência, principalmente por aparecimento de algas, melhorando assim a qualidade deste, que então responderá mais efetivamente ao reator ultravioleta na desinfecção.

Na Tabela 8 e na Figura 5 são observadas as inativações de CT e E. coli obtidas por radiação ultravioleta para o ensaio ótimo.
Tabela 8 - Remoção de Coliformes Totais e E.coli de acordo com o tempo de exposição e dose de radiação UV para o ensaio ótimo.

\begin{tabular}{cccc}
\hline Tempo & Dose & Log N/N0 & Log N/N0 \\
\hline \hline$(\mathrm{s})$ & $\left(\mathrm{mWs}^{\left.-c^{-2}\right)}\right.$ & $\underline{\mathrm{CT}}$ & $\underline{\underline{E . C o l i}}$ \\
\hline 90 & 95,13 & $-4,65$ & $-4,60$ \\
\hline 60 & 63,42 & $-4,25$ & $-4,30$ \\
\hline 40 & 42,28 & $-4,25$ & $-4,00$ \\
\hline 20 & 21,14 & $-3,47$ & $-3,12$ \\
\hline
\end{tabular}

Fonte: Os autores

Figura 5 - Inativação de CT e E.coli, com diferentes doses de radiação, para o ensaio ótimo.

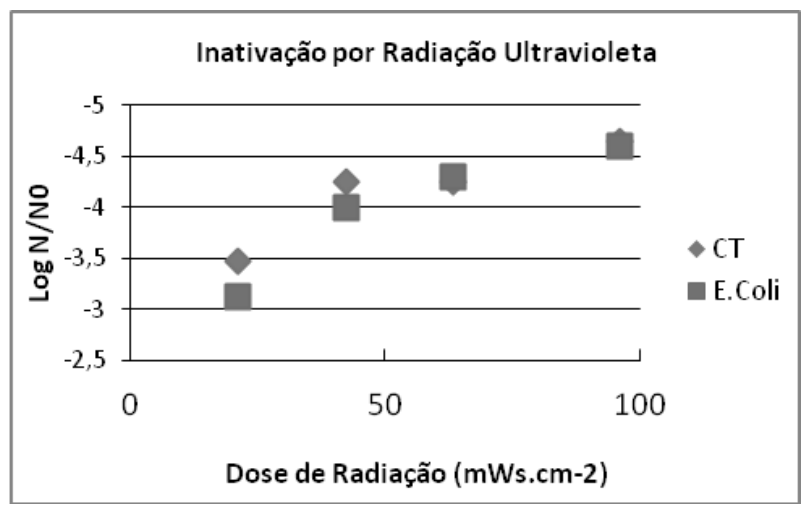

Fonte: Os autores

Os valores de CT e E. coli iniciais para o efluente da lagoa neste ensaio foram de $9.10^{5} \mathrm{UFC} / 100 \mathrm{~mL}$ e $4.10^{5} \mathrm{UFC} / 100 \mathrm{~mL}$, respectivamente. A melhor inativação coincide com a maior dose aplicada, $95,13 \mathrm{mWs} . \mathrm{cm}^{-2}$, para o maior tempo respectivo, 90 segundos de exposição, alcançando 4,65 log de inativação para Coliformes Totais (CT) e para $E$. coli $4,60 \log$.

Observa-se na Figura 5, que o gráfico apresentase linear, indicando que o efluente respondeu positivamente ao aumento sucessivo das doses de radiação. O maior residual de $E$. coli e $\mathrm{CT}$, resultante do menor tempo de exposição foi $3.10^{2} \mathrm{UFC} / 100 \mathrm{~mL}$, e, segundo Bastos (1996) apud Rocha et al., (1998) concentrações da ordem de $10^{3} \mathrm{UFC} / 100 \mathrm{~mL}$ já 
viabilizam a irrigação irrestrita, sendo perfeitamente aceitável em vários países. Desse modo a inativação mostrou-se muito eficiente para esse fim.

Silva (2007) estudando a desinfecção com radiação ultravioleta em um reator UASB combinado com biofiltro aerado submerso, obteve valores máximos de 4,12 log de inativação para coliformes totais e 4,65 log para coliformes fecais, usando lâminas líquidas de $4 \mathrm{~cm}$. Silva et al. (2002), em efluente de UASB seguido de filtro biológico percolador obteve médias de 4 a $5 \log$ de inativação de coliformes totais e E. coli, para doses variando entre 13,6 e 102,43 $\mathrm{mWs} . \mathrm{cm}^{-2}$, resultados comparáveis aos obtidos nesse estudo, inclusive quanto a dose aplicada, que variou de 21,14 a 95,13 $\mathrm{mWs} . \mathrm{cm}^{-2}$ no ensaio ótimo.

A configuração aqui apresentada para tratamento de efluente sanitário proveniente de lagoa de polimento é interessante, pois parte da premissa de que a radiação ultravioleta não se mostra eficiente na desinfecção de efluentes com alta carga de sólidos, desta forma a coagulação com cloreto férrico e polímero catiônico realizada em etapa anterior a desinfecção é uma opção atraente, eficiente e que traz benefícios, podendo ser utilizada principalmente por estações de tratamento de esgoto que em sua concepção visem o reúso, preservando ainda mais os corpos receptores.

\section{Conclusões}

Neste estudo, constatou-se a viabilidade do processo de coagulação na remoção de turbidez, DQO, cor, fósforo, sólidos totais e sólidos suspensos, quando se utilizou como coagulante cloreto férrico e também polímero catiônico. Observou-se que a presença de algas no efluente da lagoa de polimento dificultou o processo de coagulação. Com relação aos testes com polímeros, concluiu-se que a aplicação do polímero aniônico não trouxe grande contribuição na remoção da turbidez, ao contrário do polímero catiônico, que apresentou melhores resultados, corroborando com a afirmação de que as algas possuem cargas superficiais negativas e que dessa maneira foram desestabilizadas, melhorando o processo de coagulação. Na desinfecção, a melhor inativação obtida foi de 5,3 log de E. coli e 4,6 $\log$ de CT. A dosagem considerada ótima foi de $60 \mathrm{mg} . \mathrm{L}^{-1}$ de cloreto férrico aliado à $20 \mathrm{mg} . \mathrm{L}^{-1} \mathrm{de}$ polímero catiônico. Essa configuração resultou em um efluente de ótima qualidade, sendo removidos $62,7 \%$ de turbidez, $65,3 \%$ e $69,7 \%$ de cor aparente e cor verdadeira respectivamente, $50,3 \%$ de DQO e 47,3\% de sólidos suspensos e alcançou 4,65 log de inativação para CT, e 4,60 log para E. coli. Este processo então se mostrou adequado para a remoção de poluentes e microrganismos provenientes de uma lagoa de polimento, mas devem ser observadas anteriormente as características do efluente a ser desinfetado.

\section{Referências}

AGUIAR, S. M. A.; FERNANDES NETO, S. L. M.; BRITO, A. L. L.; REIS, A. A; MACHADO, R. M. P.; SOARES, S. F. A.; VIEIRA, M. C. B. M.; LIBÂNIO, M. Avaliação do Emprego da Radiação Ultravioleta na Desinfecção de Águas com Turbidez e Cor Moderadas. Engenharia Sanitária e Ambiental, Rio de Janeiro, v. 7 , n. 1, p. 37-47, jan./mar. 2002.

AISSE, M. M; JÜRGENSEN,D.; REALI, M. A. P.; PENETRA, R.; FLORENCIO, L.; SOBRINHO, P. A. Pós-Tratamento de efluentes de reatores anaeróbios por sistema de flotação. Belo Horizonte, 2001.

AMERICAN PUBLIC HEALTH ASSOCIATION. Standard methods for the examination of water and wastewater. 19. ed. Washington, 1998.

BILOTTA, P.; DANIEL, L. A. Ozônio e Radiação UV na Inativação de Indicadores Patogênicos em Esgoto Sanitário: Uma Análise Comparativa. Revista Minerva Ciência \& Tecnologia, São Carlos, v. 3, p. 199-207, 2007.

CHEN, J.-J.; YEH, H.-H. The Mechanisms of potassium permanganate on algae removal. Water Research, Oxford, v. 39, n. 18, p. 4420-4428, 2005.

CHERNICHARO, C. A. L. (Coord.). PROSAB - Póstratamento de efluentes de reatores anaeróbios. Belo Horizonte, 2001. 
CONSELHO NACIONAL DO MEIO AMBIENTE. Resolução $n^{\circ} .357$ de 17 de março de 2005: Dispõe sobre a classificação dos corpos de água e diretrizes ambientais para seu enquadramento, bem como estabelece os condições e padrões de lançamento de efluentes, e dá outras providências. Disponível em: <http://www.mma. gov.br/conama>. Brasília, 2005.

FAGUNDES, S. T. Uso de polímero natural a base de amido como auxiliar de floculação no pós-tratamento de efluentes UASB com flotação por ar dissolvido. 2010. Dissertação (Mestrado em Engenharia) - Universidade de São Paulo, São Carlos.

FERRARI, F. G.; PEREIRA, S. A.; SOUZA, C. T. E.; LIMA, P. R. M.; GONÇALVES, F. R. Pós tratamento do efluente de lagoa facultativa primária através da utilização de coagulantes metálicos e polímeros. In: CONGRESSO BRASILEIRO DE ENGENHARIA SANITÁRIA E AMBIENTAL, 23., 2005, Campo Grande. Anais... Campo Grande, 2005.

GARCIA, G. C. Pós-tratamento de efluentes de reatores anaeróbios por coagulação/precipitação seguido de radiação ultravioleta. 2010. Trabalho de Conclusão de Curso (Graduação em Engenharia Ambiental) Universidade Estadual do Centro-Oeste, Irati, 2010.

OLIVEIRA, E. C. M. Desinfecção de efluentes sanitários tratados através da radiação ultravioleta. 2003. Dissertação (Mestrado em Engenharia Ambiental) - Departamento de Engenharia Sanitária e Ambiental, Universidade Federal de Santa Catarina, Florianópolis. 2003.

QUARTAROLI, L. Aplicação da flotação por ar dissolvido como pós-tratamento de efluente de lodo ativado em uma indústria de papel e celulose. 2012. Dissertação (Mestrado em Ciências Florestais) Programa de Pós Graduação em Ciências Florestais, Universidade Estadual do Centro-Oeste, Irati.

ROCHA, F. A. L. M.; RIBEIRO, N. E.; VERONEZ, A. F.; RORIZ, M. G.; GONÇALVES, F. R. Remoção de algas, DQO, fósforo e coliformes do efluente de lagoas facultativas através de coagulação/floculação/ decantação. In: CONGRESO INTERAMERICANO DE INGENIERÍA SANITARIA Y AMBIENTAL, 26., 1998, Lima. Anais... Lima: AIDIS, 1998.

SILVA, C. C. J.; CHERNICHARO, L. A. C.; VON SPERLING, M.; ALVES, P. V. C.; ZERBINI, M. A.; GODINHO, M. V.; LAUFFER, J. Desenvolvimento e avaliação de um fotorreator simplificado de radiação UV para inativação de coliformes e ovos de helmintos em esgotos tratados. In: CONGRESO INTERAMERICANO DE INGENIERÍA SANITARIA Y AMBIENTAL, 28., 2002, Cancún. Anais... Cancun, out. 2002.
SILVA, S. S. Aplicação de radiação UV para desinfecção de efluente da associação de reator UASB e biofiltro aerado submerso. 2007. Dissertação (Mestrado em Engenharia Hidráulica e Saneamento) - Universidade de São Paulo, São Carlos.

STTIP, V.; VIDAL, C. M. S.; SOUZA, J. B; SANTOS, H. R. Avaliação da desinfecção de esgoto sanitário empregando de forma sequencial coagulação/ precipitação e ácido peracético. In: SIMPÓSIO ÍTALOBRASILEIRO DE ENGENHARIA SANITÁRIA E AMBIENTAL, 10., 2010, Maceió. Anais... Maceió, 2010.

UNITED STATES ENVIRONMENTAL PROTECTION AGENCY. Alternative disinfectants and oxidants guidance manual. Washington, 1999.

VON SPERLING, M., Introdução a qualidade das águas e ao tratamento de esgotos. Belo Horizonte: Universidade Federal de Minas Gerais, 2005. v. 1.
Recebido em 25 Novembro 2011 - Received on November 25, 2011.

Aceito em 15 Março, 2013 - Accepted on March 15, 2013. 
